УДК 624. 691.175

DOI https://doi.org/10.32838/2663-5941/2019.3-2/35

Степаненко Н.А.

Бендерский политехнический филиал

Приднестровского государственного университета имени Т.Г. Шевченко (Молдова)

\title{
Агафонова И.П.
}

Бендерский политехнический филиал

Приднестровского государственного университета имени Т.Г. Шевченко (Молдова)

Дмитриева Н.В.

Одесская государственная академия строительства и архитектуры

\section{АНАЛИЗ ВЛИЯНИЯ ТЕХНОЛОГИЧЕСКИХ ФАКТОРОВ АРМИРОВАНИЯ СКЛОНОВ ГЕОСИНТЕТИЧЕСКИМИ МАТЕРИАЛАМИ НА ИХ ПРОЧНОСТЬ}

В статье описаны основные причины потери стойкости склонов. Проведен анализ влияния конструктивно-технологических факторов на прочность откоса с иелью обнаружения тех, которые имеют наибольшее влияние. В дальнейшем планируется осуществить проверку этого влияния экспериментально. При проведении экспериментальных исследований была подготовлена экспериментальная «модель» откоса. Определены факторы, которые показали свое влияние на устойчивость армированных откосов.

Ключевые слова: армирование, геосинтетик, прочность, склоны, грунт, факторы.

Постановка проблемы. Для этого сначала рассмотрим основные причины потери стойкости склонов: старение естественной опоры массива почвы в результате разработки котлованов, траншей, подмыва откоса и т. п.; увеличение внешней нагрузки на откос (строительство сооружений на откосе или вблизи его бровки); устройство недопустимо крутого откоса; увеличение удельного веса почвы в призме обрушения в результате заполнения водой его пор (в случаях, когда почва не полностью насыщена водой); влияние повышения уровня воды на почву; увеличение гидродинамического давления воды, которая выходит через поверхность откоса; снижение сцепления и трение почвы при ее увлажнении, что часто обусловлено поднятием уровня подземных вод, а также при взрыхлении в результате промерзания и оттаивания; влияние движущегося транспорта, забивка свай, проявлении сейсмической активности и др. [1].

Нарушение прочности откосов часто является результатом нескольких причин.

Анализ последних исследований и публикаций. Одним из способов повышения устойчивости земляных откосов является их армирование геосинтетическими материалами. В последнее время такая технология получила широкое распространение [2]. Однако параметры такой технологии установлены без проведения системных научных исследований, которые бы позволили выбрать их оптимальную величину. Анализ известных исследований позволил сформулировать гипотезу о влиянии технологических факторов на показатели прочности армированных откосов. Результаты системных научных исследований дают возможность определить наиболее значимые факторы и их соотношения при установке откосов с необходимыми параметрами. Очевидно, что для разных условий устройства откосов такое соотношение будет отличаться. Использование обнаруженного оптимального соотношения факторов позволит устанавливать откосы, способные выдерживать большие нагрузки.

Постановка задания. Целью статьи является исследование конструктивно-технологических решений укрепления откосов с использованием геосинтетических материалов.

Изложение основного материала исследования. Для того чтобы разработать эффективную технологию армирования откосов с применением геосинтетических материалов, необходимо было проанализировать влияние конструктивно-технологических факторов на прочность откоса и обнаружить те, которые имеют наибольшее влияние и проверить это влияние экспериментально.

При армировании откосов геосинтетическими материалами одним из параметров, который определяет технологию процесса, является прочность 
формируемого откоса [3]. Чем большую надежность конструкции мы хотим получить, тем сильнее осложняется технологический процесс. При установке откосов, в которых угол откоса меньше или равняется углу внутреннего трения почвы, технология сводится всего лишь к отсыпанию, без принятия мер по повышению стойкости. В противном случае технология существенно изменяется. Необходимо прибегать к армированию откосов. Это ведет к повышению материалоемкости за счет внедрения в массив откоса армирующих прослоек. Также растет трудоемкость ручных работ, работы машин и механизмов. Наличие всех этих технологических процессов по увеличению прочности откосов повышенной крутизны повлияет на сроки выполнения работ.

Прочность откосов насыпи изменяется в широких пределах. В основном она зависит от таких конструктивно-технологических факторов:

- длина заведения армирующего полотна за кривую скольжения, L (мм);

- величина вертикального шага армирования, h (мм);

- количество армирующих слоев, n (шт);

- прочность армирующего материала, Rгм $(\mathrm{KH} / \mathrm{M})$;

- внешняя нагрузка, которая действует на призму обрушения откоса, $\mathrm{N}\left(\mathrm{KH}_{\mathrm{H}} \mathrm{m}^{2}\right)$;

- формируемый угол откоса (град);

- высота откоса, Н (мм);

- влажность засыпаемой почвы, w (\%);

- связность почвы;

- пористость засыпаемой почвы, n (\%);

- степень уплотнения почвы, Ку.

Условно их можно разделить на свойства почвы, армирующего материала и на конструктивно-технологические особенности армогрунтовой конструкции в целом. Каждый из перечисленных выше факторов в какой-то степени влияет на прочность откосов.

Найдено большое количество факторов, влияющих на исследуемый параметр, (прочность откоса) требовалось отобрать наиболее значимые из них. Потому что, если исследовать влияние всех факторов, количество экспериментов должно было быть непреодолимо большим. Следовательно, на первом этапе работы была сделана попытка обнаружить наиболее значимые факторы путем анализа известных исследований, сведений, опубликованных в литературных источниках и логических рассуждений.

Для выявления наиболее значимых факторов были рассмотрены каждый из них и обнаружена степень влияния на прочность. Те из них, которые в наименьшей степени влияли на общую прочность откосов, мы не включали в план экспериментальных исследований.

Одним из факторов, который существенно влияет на прочность откосов, является длина заведения армирующего геоматериала за потенциальную кривую скольжения L. Слои армирования в каждом горизонте должны пересекать потенциальные поверхности скольжения, обеспечивая при этом жесткую фиксацию их в стойкой части грунтового массива. Если не выполняется условие жесткой фиксации, то есть длина заведения армирующего материала в стойкую часть откоса не достаточна, существует опасность обрушения. При этом усилия сдвигов превосходят силы сцепления между почвой засыпки и армирующим материалом. Если делать значительный запас прочности, стойкость откоса, конечно же, будет обеспечиваться, но в этом случае возможен значительный перерасход армирующего материала. Кроме расходов на геоматериал, это влечет за собой изменение некоторых технологических параметров. Это увеличение объемов земляных работ, трудоемкости механизированных и ручных процессов. Как видно из вышесказанного, подбор оптимальной длины заведения армирующего геоматериала за потенциальную кривую скольжения является одним из наиболее значимых факторов. Следовательно, такой фактор необходимо включить в план эксперимента.

Величина вертикального шага армирования $\mathrm{h}$ практически во всех известных разработках изменялась незначительно и находилась в пределах $0,5-0,7$ м. Однако выявление оптимальной толщины армированного слоя может обеспечит уменьшение трудоемкости механизированных и ручных процессов и затраты армирующего геоматериала. Поэтому мы посчитали, что величина вертикального шага армирования является значимым фактором и ее необходимо включить в план экспериментальных исследований.

Такой фактор, как количество армируемых слоев n, зависит от высоты откоса. Он определяется как часть от высоты откоса, разделенная на вертикальный шаг армирования. Очевидно, что количество армирующих слоев влияло и на технологические показатели процесса и на прочность. С его изменением изменится много технологических параметров. Мы посчитали, что исследование влияния этого фактора на прочность откосов имеет большое практическое значение, поэтому мы включили его в план экспериментальных исследований. 
Нагрузка N, прилагаемая к откосу, в большинстве известных случаев нормальная, то есть прикладывается вертикально. В армогрунтовом массиве в процессе работы возникают касательные напряжения. Эти напряжения должны воспринимать армирующие прослойки. Изменение нагрузки может влиять на смену многих технологических факторов. С изменением нагрузки меняются и требования прочности откоса. Поэтому мы исследовали влияние нагрузки на стойкость армированного откоса.

Как говорилось выше, армирующие прослойки должны воспринимать нагрузки, которые возникают в процессе работы армогрунтовой конструкции. Поэтому очень важно было подобрать геосинтетический материал, который отвечал характеристикам по прочности и стойкости и в планируемый эксперимент включали такой фактор, как тип армирующего материала.

Формируемый угол армированного откоса в значительной мере влияет на стойкость насыпи, потому что, чем он ближе к $90^{\circ}$, тем большей становится призма обрушения. Массу почвы в объеме призмы обрушения необходимо зафиксировать. Разработка технологии армирования откосов значительной высоты с углом откоса выше, чем естественный, остается на сегодняшний день очень важным вопросам. В большинстве случаев с целью экономии полезной площади существует необходимость установки откосов с максимальным углом. Мы посчитали, что при проведении экспериментальных исследований угол откоса необходимо принимать ровным $80^{\circ}$.

Влажность грунта (W), количество воды, которая содержится в порах грунта, - величина переменная. В зависимости от климатических условий, времени года и глубины залегания грунтовых вод она может изменяться в широких пределах. При планировании экспериментальных иссле-

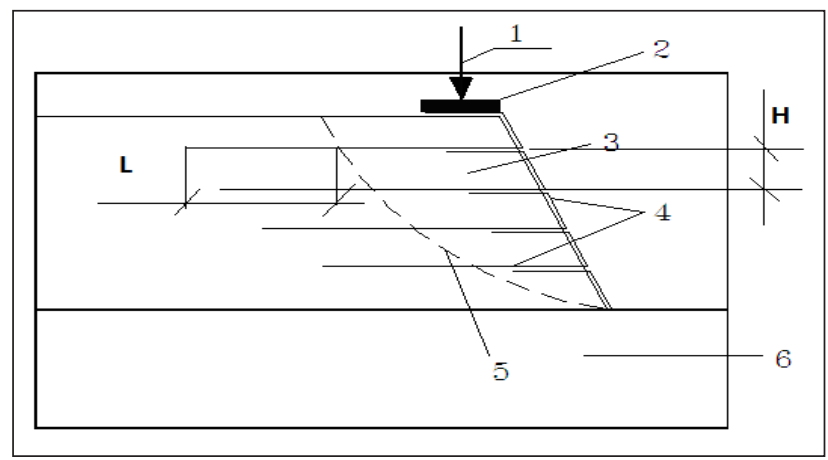

Рис. 1. Схема экспериментальной модели 1 - прилагаема нагрузка; 2 - жесткий прямоугольный штамп; 3 -призма обрушения; 4 - армирующие полотна; 5 - угол естественного откоса (кривая скольжения); 6 - толщина грунта ниже армированного откоса дований должны учитываться наиболее значимые факторы. Так как влажность может сильно изменяться, включим в план эксперимента грунт, на который изменение влажности не оказывает существенного влияния.

Связность грунтов -длина заведения армирующего полотна за кривую скольжения, L;

- величина вертикального шага армирования, $\mathrm{h}$;

- количество армируемых слоев, n.

Поэтому при проведении экспериментальных исследований проверялось влияние этих факторов на стойкость армированных откосов.

Для проведения экспериментальных исследований была подготовлена экспериментальная «модель» откоса, подлежащего укреплению, в масштабе 1:10. Размеры «ящика» для моделирования должны быть не меньше 1000х600х210 мм и откос высотой до 350 мм с углом к горизонту $80^{\circ}$. Одна из боковых граней для визуального контроля эксперимента - из прозрачного материала.

В качестве факторов приняты следующие величины:

$\mathbf{x}_{1}$-величина длины заведения геотекстиля за кривую скольжения (L).

$\mathbf{x}_{2}-$ количество армируемых слоев (n).

$\mathbf{x}_{3}$ - высота слоя армирования (h).

Наименования факторов и уровни их варьирования показаны в табл. 1.

Таблица 1

Факторы и уровни их варьирования

\begin{tabular}{|c|c|c|c|c|c|c|}
\hline \multirow[t]{2}{*}{ № } & \multirow[t]{2}{*}{ Факторы } & \multirow[t]{2}{*}{\begin{tabular}{|} 
Ед. \\
изм.
\end{tabular}} & \multirow[t]{2}{*}{ Код } & \multicolumn{3}{|c|}{$\begin{array}{c}\text { Уровни факто- } \\
\text { ров по плану } \\
\text { эксперимента }\end{array}$} \\
\hline & & & & -1 & 0 & +1 \\
\hline 1 & $\begin{array}{c}\text { Длина заведения } \\
\text { армирующего } \\
\text { полотна за кривую } \\
\text { скольжения, L }\end{array}$ & MM & $\mathbf{x}_{1}$ & 0 & 100 & 200 \\
\hline 2 & $\begin{array}{c}\text { Величина вер- } \\
\text { тикального шага } \\
\text { армирования, } \mathrm{h}\end{array}$ & MM & $\mathbf{x}_{2}$ & 50 & 60 & 70 \\
\hline 3 & $\begin{array}{l}\text { Количество } \\
\text { армируемых } \\
\text { слоев, n }\end{array}$ & Шт. & $\mathbf{x}_{3}$ & 1 & 3 & 5 \\
\hline
\end{tabular}

Экспериментальные исследования показали влияние этих факторов на устойчивость армированных откосов.

Схема экспериментальной модели представлена на рис. 1. При устройстве откоса грунт укладывался послойно с уплотнением каждого слоя. Уплотнение производилось трамбованием при помощи «штампа» весом 5 кг из условия не менее трех ударов по одному и тому же месту. 
Таблица 2

Результаты влияния факторов на устойчивость грунтовых массивов

\begin{tabular}{|c|c|c|c|c|c|c|c|c|c|}
\hline \multirow[t]{2}{*}{ № } & \multicolumn{3}{|c|}{$\begin{array}{c}\text { Кодируемые } \\
\text { значения } \\
\text { факторов }\end{array}$} & \multicolumn{3}{|c|}{$\begin{array}{c}\text { Натуральные } \\
\text { значения факторов }\end{array}$} & \multirow{2}{*}{$\begin{array}{c}\text { Нагружение, } \\
\text { которое } \\
\text { отвечает } \\
\text { началу } \\
\text { развития } \\
\text { осадки у1, кг } \\
\text { N, кг }\end{array}$} & \multirow{2}{*}{$\begin{array}{c}\text { Нагружения, } \\
\text { при которых } \\
\text { осадка достигает } \\
\text { предельно } \\
\text { допустимого } \\
\text { значения у2 (5 мм) } \\
\text { N, кг }\end{array}$} & \multirow{2}{*}{$\begin{array}{c}\begin{array}{c}\text { Нагружение, } \\
\text { которое отвечает } \\
\text { потере стойкости } \\
\text { откоса* } \mathbf{3}\end{array} \\
\text { N, кг }\end{array}$} \\
\hline & $\mathrm{x} 1$ & $\mathrm{x} 2$ & $x 3$ & $\mathrm{~L}, \mathrm{MM}$ & h, мм & n, шт. & & & \\
\hline 1 & 0 & 0 & 0 & 100 & 60 & 3 & 90 & 207 & 286 \\
\hline 2 & 1 & 1 & 1 & 200 & 70 & 5 & 82 & 177 & 239 \\
\hline 3 & 1 & -1 & -1 & 200 & 50 & 1 & 105 & 243 & 336 \\
\hline 4 & -1 & 1 & -1 & 0 & 70 & 1 & 79 & 199 & 282 \\
\hline 5 & -1 & -1 & 1 & 0 & 50 & 5 & 83 & 165 & 198 \\
\hline 6 & -1 & -1 & -1 & 0 & 50 & 1 & 92 & 223 & 314 \\
\hline 7 & 0 & -1 & 1 & 100 & 50 & 5 & 85 & 200 & 278 \\
\hline 8 & 0 & 1 & -1 & 100 & 70 & 1 & 99 & 235 & 328 \\
\hline 9 & 0 & 1 & 1 & 100 & 70 & 5 & 78 & 158 & 210 \\
\hline 10 & -1 & 0 & 1 & 0 & 60 & 5 & 74 & 147 & 173 \\
\hline 11 & 1 & 0 & -1 & 200 & 60 & 1 & 102 & 241 & 337 \\
\hline 12 & 1 & 0 & 1 & 200 & 60 & 5 & 85 & 198 & 276 \\
\hline 13 & -1 & 1 & 0 & 0 & 70 & 3 & 71 & 165 & 187 \\
\hline 14 & 1 & -1 & 0 & 200 & 50 & 3 & 94 & 236 & 335 \\
\hline 15 & 1 & 1 & 0 & 200 & 70 & 3 & 91 & 206 & 283 \\
\hline 16 & -1 & 1 & 1 & 0 & 70 & 5 & 64 & 134 & 150 \\
\hline 17 & 1 & -1 & 1 & 200 & 50 & 5 & 86 & 221 & 317 \\
\hline 18 & 1 & 1 & -1 & 200 & 70 & 1 & 101 & 239 & 333 \\
\hline
\end{tabular}

Примечание: * за потерю стойкости принималось полное обрушение откоса, или момент, когда осадка достигала 2 см.

Армирующие полотна укладывались после уплотнения каждого слоя с одновременным формированием откоса. При этом на каждый слой грунта использовалось отдельное полотно. Верхний загиб армирующего материала -5 см.

Во время эксперимента определялось влияние факторов, которые исследовались, на изменение трех показателей. Первый -

Во время эксперимента определялось влияние факторов, которые исследовались, на изменение трех показателей. Первый - количественное значение нагрузки у1(y'1), при влиянии которого начинают развиваться осадочные деформации. Второй - количественное значение величины нагрузки у2(y'2), при котором осадка достигает предельно допустимого значения. За величину предельно допустимого оседания приняты оседания, при которых не допускается нормальная эксплуатация домов и сооружений.

Третий - количественное значение нагрузки y3(y'3), при влиянии которой откос теряет стойкость и происходит его обрушение.

В качестве фактора $\mathrm{x} 1$ принята величина длины заведения геотекстиля за кривую скольжения (L). Этот фактор характеризует жесткую фиксацию армирующего материала в стойкой части грунтового массива. За стойкую часть принят грунтовый массив, расположенный за призмой обрушения. Величина х1 изменялась в пределах от 0 до 200 мм. Вторым фактором х2 была высота слоя 
армирования (h). Величина варьирования фактора от 50 до 70 мм. В качестве фактора х3, что характеризует высоту армированного откоса, принято количество армирующих слоев $\mathrm{n}$. Пределы изменения этого фактора выбраны 1, 3, 5 .

Нагрузка создавалась компрессором. Она прикладывалась через жесткий прямоугольный штамп и фиксировалась по манометру. Результаты испытания оценивались по измерению осадки штампа с помощью прогибомера ПМ-3, либо по факту потери устойчивости откоса (его обрушения) при отсутствии компрессора равномерным нагружением. Причем сначала определялся интервал нагружения опытным путем.

Эксперимент допускал реализацию серии опытов, составленных по определенной схеме: каждый из опытов отличался комбинированием независимых переменных, которые и определяли условия его проведения при сокращении объема опытных работ в сравнении с полным многофакторным экспериментом.

Данные о результатах влияния факторов, в зависимости от варьирования их уровней на устойчивость грунтовых массивов занесены в табл. 2.

Выводы. При этом выполнялись два наиболее существенных требования:

- факторы коррелируемы, то есть каждому из рассмотренных факторов можно было задать любое возможное значение, независимо от значений других переменных;

- факторы совместимы, среди возможных колебаний значений факторов, которые определяют условия каждого опыта в плане, исключены такие, которые нельзя было бы осуществить.

Выбор области изменения факторов определен теоретическими границами существования переменных, техническими возможностями и областями изменения переменных, что представляют практический интерес с точки зрения конкретного задания.

Наиболее высокая степень стойкости откоса характерна для конструктивно-технологического решения, при котором длина заведения геотекстиля за кривую скольжения равна 200 мм и уложена в один слой при высоте армирующего слоя 60 мм.

\section{Список литературы:}

1. Виды нарушения устойчивости откосов. URL: http://drillings.su/vidiotkosov.html

2. ОДМ 218.5.003-2010 Рекомендации по применению геосинтетических материалов при строительстве и ремонте автомобильных дорог Факторы, влияющие на устойчивость откосных сооружений. С. 12-23.

3. Факторы, влияющие на устойчивость откосных сооружений. URL: http://okvsk.ru/inzhenernayageologiya/900-faktory-vliyayuschie-na-ustoychivost-otkosnyh-sooruzheniy.html.

4. Методика расчета насыпей, армированных различными материалами. URL: https://files.stroyinf.ru/ Data2/1/4293853/4293853598.htm.

5. Воронюк Б.А., Буянов А.И. Физико-механические свойства растений, почв и удобрений. Москва : Колос, 1970. С. 127-133.

6. Плотность грунтов. Пористость и степень уплотнения. URL: https:/lektsii.com/2-125161.html

\section{АНАЛІЗ ВПЛИВУ ТЕХНОЛОГІЧНИХ ЧИННИКІВ АРМУВАННЯ СХИЛІВ ГЕОСИНТЕТИЧНИХ МАТЕРІАЛІВ НА ЇХ ПРОЧНОСТЬ}

У статті описані основні причини втрати стійкості схилів. Проведено аналіз впливу конструктивно-технологічних факторів на міцність укосу з метою виявлення тих, які мають найбільший вплив. Надалі планується здійснити перевірку иьього впливу експериментально. Під час проведення експериментальних досліджень була підготовлена експериментальна «модель» укосу. Визначено фактори, які показали свій вплив на стійкість армованих укосів.

Ключові слова: армування, геосинтетики, міцність, схили, трунт, фактори.

\section{IMPACT ANALYSIS OF TECHNOLOGICAL FACTORS OF REINFORCING SLOPES WITH GEOSYNTHETIC MATERIALS ON THEIR DURABILITY}

This article describes the main causes of loss of slope resistance power. The analysis of the influence of constructive-technological factors on the strength of the slope in order to detect those that have the greatest impact. In the future, to verify this effect experimentally An experimental slope "model" was prepared for these experimental investigations. The factors that have shown their influence on the stability of reinforced slopes are determined.

Key words: reinforcement, geosynthetics, strength, slopes, soil, factors. 